\title{
A importância da segregação do agregado reciclado na resistência e na durabilidade do concreto estrutural
}

\author{
The role of recycled aggregate segregation on the \\ strength and durability of structural concrete
}

\begin{tabular}{|c|c|}
\hline & $\begin{array}{l}\text { Pedro Valle Salles } \\
\text { Camila Lacerda Gomes iD } \\
\text { Flávia Spitale Jacques Poggiali iD } \\
\text { Conrado de Souza Rodrigues (iD } \\
\text { Resumo }\end{array}$ \\
\hline & $\begin{array}{l}\text { heterogeneidade dos resíduos de construção e demolição dificulta seu } \\
\text { uso sistemático, consequentemente, têm-se problemas com a } \\
\text { disposição final e a contínua extração e uso de recursos não renováveis } \\
\text { para fabricação de concretos. Essa heterogeneidade decorre, }\end{array}$ \\
\hline 1, 2Pedro Valle Salles & $\begin{array}{l}\text { Palavras-chave: Segregação de resíduos de construção e demolição. Concreto. } \\
\text { Durabilidade. Caracterização Mecânica. }\end{array}$ \\
\hline $\begin{array}{l}\text { 'Centro Federal de Educação } \\
\text { Tecnólogica de Minas Gerais } \\
\text { Belo Horizonte - MG - Brasil }\end{array}$ & Abstract \\
\hline $\begin{array}{r}\text { 2Universidade do Estado de Minas } \\
\text { Gerais } \\
\text { João Monlevade - MG - Brasil }\end{array}$ & $\begin{array}{l}\text { The great heterogeneity of construction and demolition waste }(C D W) \text { hinders } \\
\text { its systematic use, leading to problems in its final disposal and in the continual } \\
\text { extraction and use of non-renewable resources in concrete manufacturing. }\end{array}$ \\
\hline $\begin{array}{l}{ }^{3} \text { Camila Lacerda Gomes } \\
{ }^{3} \text { Centro Federal de Educação } \\
\text { Tecnólogica de Minas Gerais } \\
\text { Belo Horizonte - MG - Brasil }\end{array}$ & $\begin{array}{l}\text { This heterogeneity derives primarily from the fact that manufacturers do not } \\
\text { segregate the wide variety of CDW components during their processing. This } \\
\text { paper analyses the need to segregate CDW into two different types - clay } \\
\text { ceramics (red) and rocks and cement (gray) - and the consequences of using } \\
\text { these materials as substitutes for natural coarse aggregates in structural }\end{array}$ \\
\hline $\begin{array}{r}{ }^{4} \text { Flávia Spitale Jacques Poggiali } \\
{ }^{4} \text { Centro Federal de Educação } \\
\text { Tecnólogica de Minas Gerais } \\
\text { Belo Horizonte - MG - Brasil }\end{array}$ & $\begin{array}{l}\text { concrete. Hence, different concretes were manufactured with } 25,50 \text { and } 100 \% \\
\text { CDW, using three types of waste: cementitious, ceramic and a mixture of both. } \\
\text { The conclusion is that it is not necessary to segregate the waste from the } \\
\text { recycling plant, since the results show that the concrete with cementitious }\end{array}$ \\
\hline $\begin{array}{l}{ }^{5} \text { Conrado de Souza Rodrigues } \\
{ }^{5} \text { Centro Federal de Educação } \\
\text { Tecnólogica de Minas Gerais } \\
\text { Belo Horizonte - MG - Brasil }\end{array}$ & $\begin{array}{l}\text { aggregates and the one with mixed aggregates perform similarly. In addition, } \\
\text { the use of CDW affects the characteristics of the concrete. Rheological and } \\
\text { mechanical performance are parameters negatively affected by the use of } \\
\text { waste. However, durability may improve with the use of recycled aggregates. }\end{array}$ \\
\hline $\begin{array}{r}\text { Recebido em } 18 / 03 / 20 \\
\text { Aceito em } 03 / 08 / 20\end{array}$ & $\begin{array}{l}\text { Keywords: Construction and demolition waste. Concrete. Durability. Mechanical } \\
\text { characterization. }\end{array}$ \\
\hline
\end{tabular}

SALLES, P. V.; GOMES, C. L.; POGGIALI, F. S. J.; RODRIGUES, C. de S. A importância da segregação do agregado reciclado na resistência e na durabilidade do concreto estrutural. Ambiente Construído, Porto Alegre, v. 21, n. 3, p. 177-196, jul./set. 2021.

ISSN 1678-8621 Associação Nacional de Tecnologia do Ambiente Construído. http://dx.doi.org/10.1590/s1678-86212021000300545 


\section{Introdução}

O concreto e a argamassa, assim como os resíduos cerâmicos, provenientes pincipalmente de alvenarias e revestimentos, constituem a maior parte do que é chamado de resíduos de construção e demolição (RCD). As enormes quantidades produzidas desses resíduos se tornaram um problema com vertentes social e ambiental de difícil solução, principalmente no que tange à sua disposição final. Os RCD são responsáveis por aproximadamente $50 \%$ do volume total de resíduo produzido nos grandes centros urbanos (DUAN et al., 2020b; RYOU; LEE, 2014; XIAO et al., 2018a; ZHANG et al., 2015). Ainda nesse sentido, os produtos cimentícios são os materiais de construção civil mais importantes e utilizados no mundo. Esse uso massivo implica um número cada vez maior de recursos naturais sendo extraídos e utilizados, causando sua consequente e crescente escassez (PEDRO; DE BRITO; EVANGELISTA, 2014; PROŠEK et al., 2019; SHI et al., 2015).

A geração de RCD e a demanda crescente por recursos não renováveis são problemas globais, que requerem soluções específicas e urgentes (XIAO et al., 2018b). Em diversos países do mundo, já é possível encontrar normatização referente à fabricação de concretos estruturais com agregados reciclados (AR), contudo essa viabilidade se encontra, na maioria das vezes, ligada à segregação das diversas frações constituintes dos resíduos. Entre os benefícios do reúso/reciclagem dos RCD, encontram-se o aumento da vida útil dos aterros, a diminuição da ocorrência de deposições irregulares, a redução do consumo de recursos naturais não renováveis, a redução dos impactos da construção civil no meio ambiente e a criação de novas cadeias produtivas, gerando economia e empregos (CORINALDESI; MORICONI, 2009; DE BRITO; DOMINGUES DE FIGUEIREDO; JOHN, 2020).

Apesar de estar pautado em uma sólida fundamentação teórica e técnica, o uso de AR ainda encontra diversas barreiras. É notória a grande variabilidade desses resíduos, principalmente quando não há separação na fonte geradora, como no caso brasileiro (ANGULO et al., 2009; HENDRIKS; NIJKERK; VAN KOPPEN, 2007; LIU et al., 2014). A Resolução n 307 do Conselho Nacional do Meio Ambiente (CONAMA) não propõe a separação dos diversos tipos de materiais passíveis de serem reciclados como agregados. Na prática, esse fato torna o comportamento dos concretos fabricados com agregados de RCD de difícil previsão. Além disso, essa mesma normativa classifica como "Tipo A" os resíduos passíveis de serem utilizados como agregados de concreto e solos, que não se adequam à utilização supracitada (BRASIL, 2002).

Outra questão que dificulta o emprego dos AR é a variabilidade de resultados apresentados pela literatura científica. Essa diversidade se deve, justamente, às variadas possibilidades de utilização dos resíduos. Ainda não há consenso sobre qual é o efeito do uso desses resíduos na performance dos concretos fabricados. Se, por um lado, há um avanço maior no estudo das características reológicas e mecânicas, por outro, ainda são necessárias maiores investigações sobre a durabilidade desses concretos com adição de resíduos.

O presente artigo tem como objetivo avaliar a necessidade de segregação das diversas frações que compõem o agregado reciclado, quando da utilização desses em concreto. Concomitantemente, visa explicar o comportamento mecânico e de durabilidade, em relação a um concreto referência (CR), de concretos fabricados com a substituição (de 25, 50 e 100\%) do agregado graúdo natural por AR de RCD.

\section{Resíduos de construção e demolição}

É notória a diferença de desempenho dos agregados de RCD em comparação aos agregados naturais (AN) na confecção de concreto. Com isso, compreender a constituição dos RCD é fundamental para julgar a real necessidade de sua segregação, de forma que as características do concreto final sejam mais previsíveis. De acordo com Hendriks, Nijkerk e van Koppen (2007), o momento e o local ideais para segregação dos RCD é na própria fonte de resíduos no momento de sua concepção, pois, uma vez misturados, é muito difícil realizar a separação completa dos diversos materiais constituintes. Há sempre uma predileção pelos agregados cimentícios/rochosos, sendo sua utilização normatizada em grandes teores; por outro lado, restringe-se a utilização da fração vermelha dos RCD (ROBAYO-SALAZAR; RIVERA; MEJÍA DE GUTIÉRREZ, 2017).

Os resíduos de construção e de demolição, mesmo quando segregados, apresentam características que diferem das propriedades dos agregados naturais. Muito dessa discrepância está relacionada à composição dos AR - majoritariamente cerâmicas vermelhas e materiais cimentícios - que apresentam propriedades muito díspares quando comparadas às rochas naturais. Outra questão relevante é a presença de argamassa aderida em parte dos agregados reciclados, dado que traz com ela propriedades como alta porosidade e baixa

178 Salles, P. V.; Gomes, C. L.; Poggiali, F. S. J.; Rodrigues, C. de S. 
resistência à abrasão e compressão quando comparada aos AN. Além disso, introduz-se na mistura uma quantidade de zonas de transição interfacial (ZTI) (DUAN et al., 2020a; FERREIRA; BARRA; DE BRITO, 2011; KOU; POON; ETXEBERRIA, 2011; THOMAS et al., 2020).

Estudos confirmam que os agregados provenientes de RCD apresentam menor massa específica, maior porosidade e, consequentemente, maior absorção de água (ETXEBERRIA et al., 2007). A principal causa dessa perda de desempenho seriam os constituintes dos resíduos. No caso de presença de cerâmica vermelha, esse material apresenta pior desempenho tanto em relação aos $\mathrm{AN}$ quanto em relação aos resíduos cimentícios (ALIABDO; ABD-ELMOATY; HASSAN, 2014).

\section{Concretos com resíduos de construção e demolição}

Com relação ao desempenho dos concretos fabricados com $\mathrm{AR}$, há demanda por adequações nos métodos de dosagem que possibilitem a consideração dos resíduos. Enquanto há relatos sobre perda de desempenho mecânico e de durabilidade, existem também indícios da manutenção das características e, em alguns casos, até de melhorias na performance dos concretos.

Diversas características nos concretos fabricados podem influenciar na maneira como ele se comporta, como o grau de substituição dos AN por agregados provenientes de RCD, a existência - ou não - de pré-saturação dos mesmos, o fator água/cimento (fator $\mathrm{A} / \mathrm{C}$ ), a presença de adições minerais, o uso de aditivos, entre outros.

\section{Comportamento do concreto fresco}

Devido à alta porosidade e absorção de água - características comuns nos agregados reciclados -, é muito corriqueira a alteração de características do concreto em estado fresco, principalmente no que tange à trabalhabilidade. O AR, por ser mais absorvente, tende a reter uma maior quantidade de água da mistura, diminuindo a trabalhabilidade, podendo essas perdas variarem de 4 a 64\% (MATIAS et al., 2014; ZHANG; ZONG, 2013).

A pré-saturação dos agregados tem grande importância na trabalhabilidade do concreto; agregados provenientes de RCD pré-molhados tendem a absorver menor quantidade de água da mistura e, assim, melhoram a trabalhabilidade do concreto. Ferreira, Barra e de Brito (2011) e Etxeberria et al. (2007) utilizam técnicas de pré-saturação dos AR em seus estudos; os resultados de ambos os estudos apontam para a manutenção da trabalhabilidade das misturas.

Outra maneira de amenizar o problema da perda de trabalhabilidade é a utilização de aditivos. Matias et al. (2014) confirmam o acréscimo do abatimento do tronco de cone causado por aditivos superplastificantes (SP I, à base de polímeros orgânicos, e SP II, à base de policarboxilato). Entre os concretos com uso dos aditivos, quanto maior o teor de substituição dos AN por AR, menor a trabalhabilidade. Contudo, quando comparados aos concretos com AR e sem aditivos, é relevante a melhoria de desempenho.

\section{Comportamento do concreto endurecido}

O teor de substituição do AN por agregados de RCD tem influência sobre a resistência à compressão do concreto. Kou e Poon (2012) indicam perda de resistência à compressão com o aumento de AR na mistura, aos 10 anos de idade, têm-se 67,50 MPa para o CR, e 57,50 MPa e 52,2 MPa para os concretos com 50\% e $100 \%$ de AR cimentício, respectivamente (KOU; POON, 2012). Contudo, outros estudos afirmam que, em baixos teores de substituição, a perda de resistência é pouco significativa, isto é, aumentando-se o teor de substituição, a resistência tende a diminuir (THOMAS et al., 2012). Limbachiya (2004) expõe que, com um mesmo fator $\mathrm{A} / \mathrm{C}$, concretos com mais de $30 \%$ de $\mathrm{AR}$ apresentavam menor resistência à compressão, enquanto os traços com $20 \%$ de agregado de RCD apresentavam desempenhos semelhantes à referência, o que indica desempenho mecânico satisfatório das misturas. De acordo com o autor, concretos com 30\% ou mais de AR se mostraram menos fluídos, coesos e resistentes (LIMBACHIYA, 2004).

Com relação à absorção de água e à porosidade, a taxa de utilização de agregados provenientes de RCD se apresenta como uma variável importante. O AR, mais poroso e com maior absorção que o AN, pode transferir suas características ao concreto que o utiliza. Estudos afirmam que, em concretos com até $20 \%$ do AN substituído por AR, é possível obter baixa porosidade e absorção de água e que acima desse teor, quanto mais resíduos, maior é a porosidade e a absorção de água. Quanto maior é a quantidade de resíduos, maior é 
a porosidade, na interface do agregado, do concreto endurecido, essa tendência é mais presente em idades mais jovens (LEVY; HELENE, 2004).

A respeito da resistência à tração, Kou, Poon e Etxeberria (2011), Kou e Poon (2012) e Zhang e Zong (2013) apontam que o uso de agregado de RCD em substituição ao AN não influencia a performance do concreto fabricado e que em alguns casos pode até melhorar o desempenho. Hipóteses levantadas que justificam esse comportamento são melhorias na microestrutura do concreto, principalmente na ZTI, e uma menor solicitação dos AR, em comparação à compressão, nos ensaios de tração.

Com relação ao avanço da frente de carbonatação, os resultados se mostram diversificados. Parte dos autores acreditam que a velocidade da frente de carbonatação está ligada à porosidade dos agregados reciclados e que ela, por sua vez, está relacionada com a qualidade e origem dos resíduos (OTSUKI; MIYAZATO; YODSUDJAI, 2003; WERLE; KAZMIERCZAK; KULAKOWSKI, 2011).

Outro ponto de fundamental importância é o fator $\mathrm{A} / \mathrm{C}$, sendo que a elevação ou diminuição dessa relação proporcionará uma matriz cimentícia com mais ou menos poros e, com isso, uma maior ou menor carbonatação. Alguns autores apontam manutenção do desempenho com relação à carbonatação (EGUCHI et al., 2007; GOMES; DE BRITO; BRAVO, 2009). O AR, ao absorver água de amassamento, pode tornar a matriz menos porosa e mais resistente à carbonatação, diminuindo a relação $\mathrm{A} / \mathrm{C}$ efetiva. Além disso, pode haver adição de álcalis extras, advindos de adição de resíduos cimentícios (CORINALDESI; MORICONI, 2009).

\section{Materiais e métodos}

\section{Obtenção, lavagem, separação das frações dos RCD e definição de nomenclatura}

O RCD utilizado no trabalho foi obtido diretamente com a Superintendência de Limpeza Urbana de Belo Horizonte (SLU-BH), na Central de Tratamento de Resíduos Sólidos da BR-040.

A separação dos resíduos de construção e demolição resultou na criação de quatro classes de materiais que, de agora em diante, no escopo desse trabalho, passam a ser denominadas agregado reciclado cinza (ARC), agregado reciclado vermelho (ARV), agregado reciclado misto (ARM) e resíduos descartados. O Quadro 1 apresenta a constituição de cada uma dessas classes.

A lavagem do agregado foi realizada por meio de agitação do material em água, o que permitiu sua posterior classificação e segregação. A segregação ocorreu por processo de catação em mesa com fundo branco. Todo o material que não encaixou em nenhuma das classes propostas de agregados reciclados (ver Quadro 1) foi descartado. A Figura 1 ilustra os agregados após procedimento descrito.

As proporções de cada uma das frações de RCD no material após lavagem são 82,00\% de ARC, 15,68\% de ARV e $2,32 \%$ de resíduos descartados. A proporção de ARC e de ARV contidos no ARM é aquela que ocorre no material bruto, exceto contaminantes. Com a exclusão dos resíduos descartados, o ARM é constituído por $83,94 \%$ de ARC e $16,06 \%$ de ARV.

Quadro 1 - Constituição das classes de agregados reciclados

\begin{tabular}{|c|c|c|c|}
\hline ARC & ARV & ARM & Resíduos descartados \\
\hline \multirow{5}{*}{ Rochas naturais } & \multirow{5}{*}{$\begin{array}{l}\text { Cerâmicas vermelhas e } \\
\text { de revestimento }\end{array}$} & \multirow{9}{*}{$\mathrm{ARV}+\mathrm{ARC}$} & Vidro \\
\hline & & & Prego \\
\hline & & & Arame \\
\hline & & & Plástico \\
\hline & & & PVC \\
\hline \multirow{4}{*}{ Materiais cimentícios } & \multirow{4}{*}{$\begin{array}{l}\text { Materiais cimentícios } \\
\text { aderidos às cerâmicas }\end{array}$} & & Madeira \\
\hline & & & Borracha \\
\hline & & & Betume (asfalto) \\
\hline & & & Não identificados \\
\hline
\end{tabular}

Nota: Legenda:

ARC: agregado reciclado cinza;

$A R V$ : agregado reciclado vermelho;

ARM: agregado reciclado misto; e

PVC: policloreto de vinila.

180 Salles, P. V.; Gomes, C. L.; Poggiali, F. S. J.; Rodrigues, C. de S. 
Figura 1 - Agregado reciclado lavado, segregado e seco: (a) ARV e (b) ARC

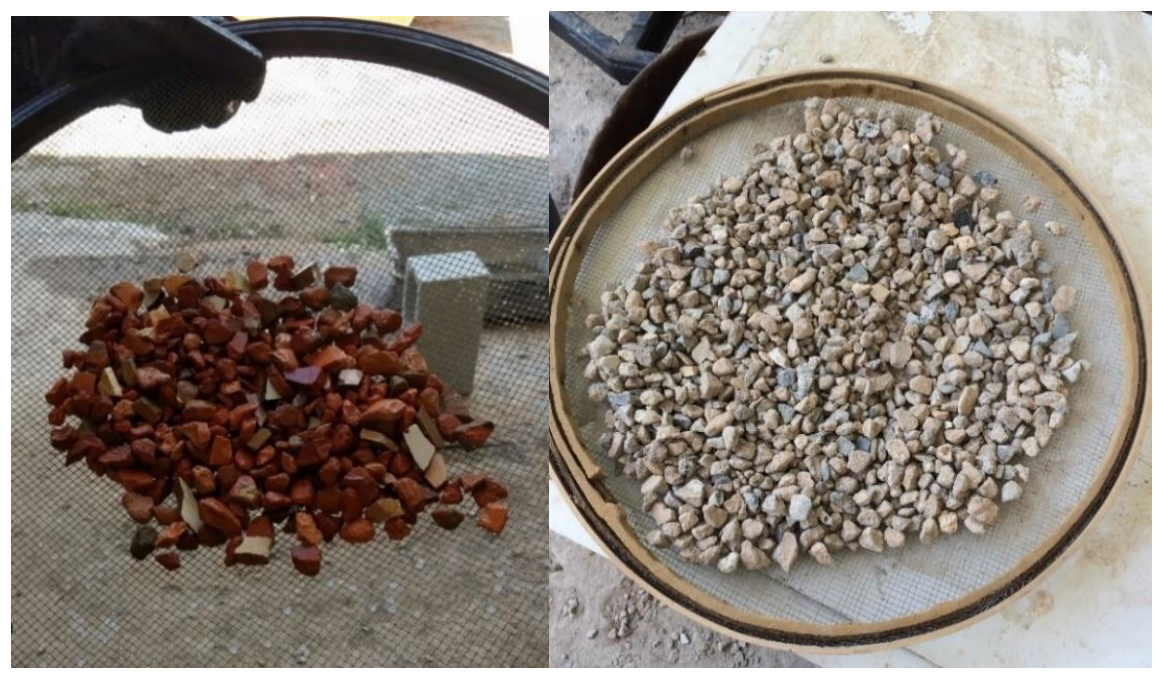

(a) ARV

(b) ARC

Agrela et al. (2011) relatam porcentagens semelhantes às apresentadas. De acordo com os autores, porcentagens usuais de um RCD seriam $80 \%$ de resíduos de concreto ou rochas naturais, de 10 a $15 \%$ de resíduos de cerâmicas ou alvenaria, de 3 a $8 \%$ de resíduos asfálticos e de 2 a $6 \%$ de impurezas em geral (AGRELA et al., 2011).

\section{Cimento}

O tipo de cimento utilizado na pesquisa foi o CP V-ARI, que apresenta densidade de 2,973 g/cm - aferida por picnometria a gás hélio - e área específica de Blaine de $4753 \mathrm{~cm} / \mathrm{g}$ (HOLCIM, 2017). A Tabela apresenta a composição química do material.

\section{Agregados graúdos}

Os quatro tipos de agregados graúdos utilizados nesse trabalho (AN, ARC, ARM e ARV) foram caracterizados por meio de normas brasileiras ou por literatura que descreva a metodologia específica necessária ao ensaio. O Quadro 2 apresenta os ensaios realizados e suas respectivas normas e referências. Como citado, os AR foram obtidos em usinas de reciclagem, já os AN foram obtidos em depósitos de materiais de construção, sendo rocha gnaisse britada, ambos foram secos em estufa antes da utilização.

Com o intuito de servir de base para o procedimento de dosagem do concreto, a Tabela 2 apresenta as principais características dos AN necessárias no procedimento. A apresentação, comparação e análise completa da caracterização dos agregados graúdos estão detalhadas na seção "Resultados e Discussões".

\section{Agregados miúdos}

A areia, lavada de rio, foi obtida em depósito de materiais de construção. Os agregados miúdos foram caracterizados por meio das normas NBR NM 248 (ABNT, 2003b), NBR 9776 (ABNT, 1987) e NBR NM 45 (ABNT, 2006). Para a massa específica do agregado miúdo, o valor encontrado foi de $2,58 \mathrm{~g} / \mathrm{cm}^{3}$. O valor determinado para massa unitária do agregado miúdo é de $1393,68 \mathrm{~kg} / \mathrm{m}^{3}$, e o índice de vazios do material é de $45,81 \%$.

O módulo de finura do agregado miúdo foi considerado dentro da zona utilizável, com o valor de 3,04. De acordo com a NBR 7211 (ABNT, 2009a), os limites da distribuição granulométrica do agregado miúdo em questão se encontram majoritariamente dentro da zona utilizável e em algumas peneiras na zona ótima.

\section{Aditivo superplastificante}

Tendo em vista a notória diminuição de trabalhabilidade nos concretos com utilização de AR, optou-se pela utilização de aditivo. O escolhido foi o Fluxer RMX 7000, sendo um superplastificante tipo II retardador de pega (SP-II R). Os SP-II são considerados aditivos que, sem modificar a consistência do concreto no estado 
fresco, permitem uma elevada redução do conteúdo de água de um concreto, ou que, sem alterar a quantidade de água, aumentam consideravelmente o abatimento e a fluidez do concreto. De acordo com a Erca (2016), esse tipo de aditivo permite a redução de até $35 \%$ de água, uma altíssima manutenção da trabalhabilidade e uma boa resistência inicial. O Fluxer RMX 7000 apresenta uma coloração castanho claro, densidade de 1,07 a $1,11 \mathrm{~g} / \mathrm{cm}$ e sua dosagem sugerida varia de 0,5 a $1,0 \%$ da quantidade de cimento utilizado.

De acordo com o fabricante, o aditivo deve ser adicionado junto com a segunda água de amassamento, com o intuito de evitar absorção por parte dos agregados (ERCA, 2016). A dosagem do SP-II R, que se calcula pelo peso do cimento consumido, foi estabelecida nos valores de $0,6 \%$ e $1,0 \%$ para concretos sem adição de AR e de 1,0\% para agregados com uso de AR. Essa dosagem foi definida considerando os resultados de Slump obtidos em moldagens preliminares, onde moldou-se um concreto, sem presença de agregados proveniente de RCD, com teor de $1 \%$ de aditivo.

\section{Dosagem do concreto}

O método de dosagem escolhido foi o do American Concrete Institute. A Tabela 3 expõe o traço definido para o concreto em estudo e os consumos de cada material por metro cúbico de concreto.

Os AN foram substituídos em volume (25, 50 e 100\%) pelos AR. Essa escolha se deve ao fato de, por terem uma densidade menor, ao serem substituídos utilizando a massa, ocupariam um volume maior na mistura (PACHECO-TORGAL et al., 2013). Optou-se pela não saturação dos AR antes da mistura, essa decisão visa aproximar a moldagem em laboratório de algo mais comumente utilizado, na prática, nos canteiros de obra. O Quadro 3 apresenta os traços fabricados e as siglas adotadas para cada um deles daqui em diante.

\section{Moldagem e cura dos corpos de prova}

O método de mistura escolhido foi o método de mistura dupla (em inglês, double mixing method ou twostage mixing). Otsuki, Miyazato e Yodsudjai (2003) relatam melhorias na resistência mecânica e na resistência à penetração de íons cloreto e à carbonatação em concretos com $\mathrm{AR}$ e relação $\mathrm{A} / \mathrm{C}$ de 0,55 . Além disso, essa metodologia visa diminuir a quantidade de água absorvida pelos AR. A Figura 2 ilustra o procedimento de mistura.

Tabela 1 - Composição química do CP V-ARI

\begin{tabular}{c|c|c|c|c|c|c|c}
\hline & $\mathbf{C a O}$ & $\mathrm{SiO}_{2}$ & $\mathbf{A l}_{2} \mathrm{O}_{3}$ & $\mathbf{F e}_{2} \mathbf{O}_{3}$ & $\mathbf{S O}_{3}$ & $\mathbf{K}_{2} \mathrm{O}$ & $\mathbf{M g O}$ \\
\hline Cimento (\%) & 64,17 & 18,93 & 5,16 & 2,96 & 2,88 & 0,86 & 0,76 \\
\hline
\end{tabular}

Fonte: Holcim (2017).

Quadro 2 - Ensaios e normas de caracterização do agregado graúdo

\begin{tabular}{|l|l|}
\hline \multicolumn{1}{|c|}{ Ensaio } & \multicolumn{1}{c|}{ Norma/Referência } \\
\hline Determinação da composição e curva granulométrica & NBR MN 248 (ABNT, 2003b) \\
\hline $\begin{array}{l}\text { Determinação de massa específica, massa específica } \\
\text { aparente e absorção de água }\end{array}$ & NBR NM 53 (ABNT, 2009c) \\
\hline Determinação da massa unitária e do volume de vazios & NBR NM 45 (ABNT, 2006) \\
\hline Ensaio de abrasão "Los Angeles” & NBR NM 51 (ABNT, 2001) \\
\hline Curva de absorção de água dos agregados graúdos & Leite (2001) \\
\hline
\end{tabular}

Fonte: ABNT (2003b, 2009c, 2006, 2001) e Leite (2001).

Tabela 2 - Características do AN utilizadas na dosagem do concreto

\begin{tabular}{c|c|c|c}
\hline Classificação & $\begin{array}{c}\text { Massa específica } \\
\left(\mathbf{g} / \mathbf{c m}^{\mathbf{3}}\right)\end{array}$ & $\begin{array}{c}\text { Massa unitária } \\
\left(\mathbf{g} / \mathbf{c m}^{\mathbf{3}}\right)\end{array}$ & $\begin{array}{c}\text { Diâmetro máximo } \\
\text { característico }(\mathbf{m m})\end{array}$ \\
\hline Brita 1 & 2,66 & 1,44 & 25 \\
\hline
\end{tabular}

Tabela 3 - Dosagem do concreto e consumo por $\mathrm{m}^{3}$

\begin{tabular}{c|c|c|c|c}
\hline & Cimento & Areia & Brita & Água \\
\hline Traço & $1(364 \mathrm{~kg} / \mathrm{m})$ & $2,16(785 \mathrm{~kg} / \mathrm{m})$ & $2,73(994 \mathrm{~kg} / \mathrm{m})$ & $0,55(200 \mathrm{~kg} / \mathrm{m})$ \\
\hline
\end{tabular}

182 Salles, P. V.; Gomes, C. L.; Poggiali, F. S. J.; Rodrigues, C. de S. 
Quadro 3 - Traços fabricados e as respectivas siglas adotadas

\begin{tabular}{|c|c|}
\hline Traço fabricado & Sigla adotada \\
\hline Concreto de referência com $0 \%$ de agregado reciclado & CR \\
\hline Concreto reciclado com $25 \%$ de agregado cinza & $25 \%$ ARC \\
\hline Concreto reciclado com $50 \%$ de agregado cinza & $50 \%$ ARC \\
\hline Concreto reciclado com $100 \%$ de agregado cinza & $100 \%$ ARC \\
\hline Concreto reciclado com $25 \%$ de agregado misto & $25 \% \mathrm{ARM}$ \\
\hline Concreto reciclado com $50 \%$ de agregado misto & $50 \% \mathrm{ARM}$ \\
\hline Concreto reciclado com $100 \%$ de agregado misto & $100 \% \mathrm{ARM}$ \\
\hline Concreto reciclado com $25 \%$ de agregado vermelho & $25 \% \mathrm{ARV}$ \\
\hline Concreto reciclado com $50 \%$ de agregado vermelho & $50 \% \mathrm{ARV}$ \\
\hline Concreto reciclado com $100 \%$ de agregado vermelho & $100 \% \mathrm{ARV}$ \\
\hline
\end{tabular}

Nota: Legenda:

CR: concreto de referência;

ARC: agregado reciclado cinza;

ARM: agregado reciclado misto; e

ARV: agregado reciclado vermelho.

Figura 2 - Método de mistura dupla

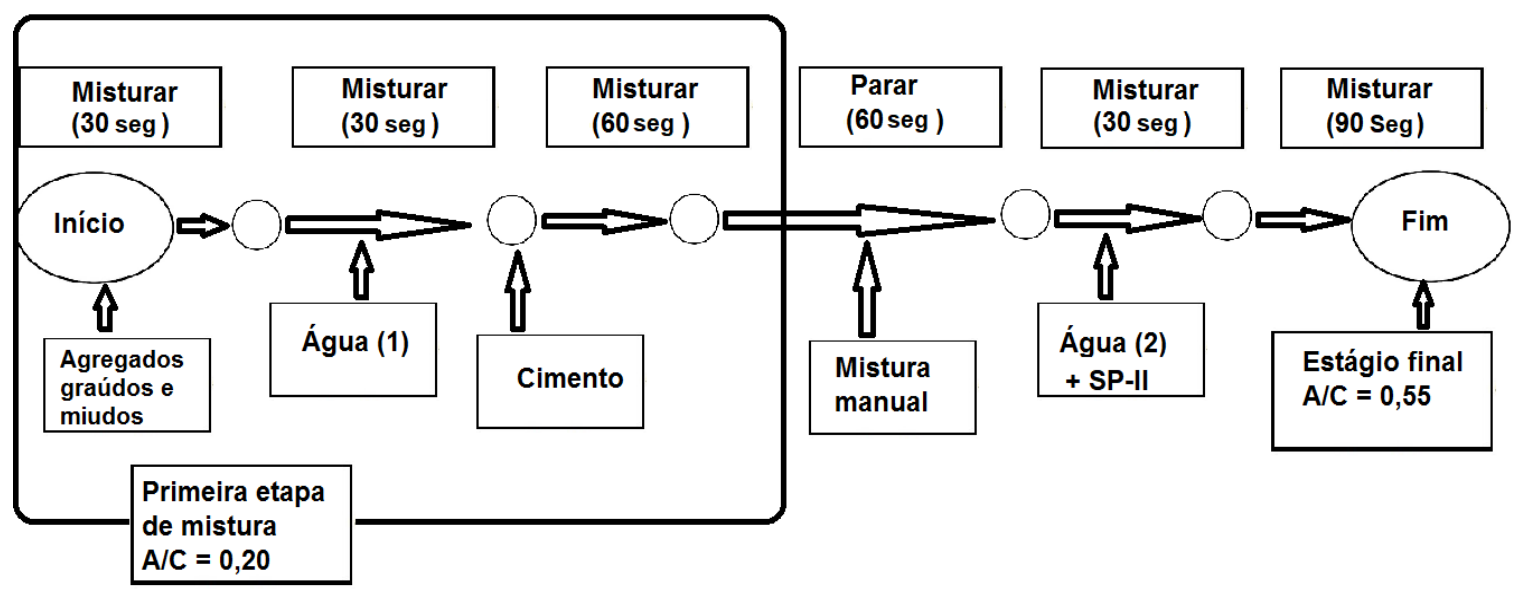

Fonte: adaptado de Otsuki, Miyazato e Yodsudjai (2003).

O adensamento dos corpos de prova (CP) foi realizado em mesa vibratória, em duas camadas de preenchimento. $\mathrm{O}$ capeamento dos $\mathrm{CP}$ foi realizado com enxofre. Os CP, desmoldados depois de 24 horas, ficaram em cura submersa, em solução saturada de hidróxido de cálcio, até a idade de 28 dias, conforme NBR 5738 (ABNT, 2003a).

\section{Caracterização do concreto}

Os dez traços fabricados nesse trabalho foram caracterizados por meio de normas brasileiras, quando disponíveis, ou por normatização internacional. O Quadro 4 apresenta os ensaios realizados e suas respectivas normas. Também apresenta a quantidade de $\mathrm{CP}$ utilizados em cada ensaio, bem como a idade do concreto, a partir da moldagem, em cada procedimento.

Para o ensaio de carbonatação, a câmara de ensaio acelerado foi configurada para $20{ }^{\circ} \mathrm{C}$, umidade relativa de $65 \%$ e concentração de $\mathrm{CO}_{2}$ de $5 \%$. Os $\mathrm{CP}$ destinados a esse ensaio passaram por período de sazonamento por 14 dias, em ambiente de laboratório. Após esse procedimento, o concreto foi colocado na câmara de carbonatação acelerada por período de 90 dias, data onde se realizou o teste com fenolftaleína. No caso dos ensaios mecânicos, utilizou-se uma prensa da marca EMIC, com capacidade de $2000 \mathrm{kN}$. 
Quadro 4 - Ensaios de caracterização do concreto

\begin{tabular}{|l|l|c|c|}
\hline \multicolumn{1}{|c|}{ Ensaio } & \multicolumn{1}{|c|}{ Norma } & $\begin{array}{c}\text { Número de CP por } \\
\text { idade e formulação }\end{array}$ & Idade \\
\hline $\begin{array}{l}\text { Consistência pelo abatimento } \\
\text { do tronco de cone }\end{array}$ & NBR MN 67 (ABNT, 1998) & - & - \\
\hline Resistência à compressão & NBR 5739 (ABNT, 2018) & 3 & 28 \\
\hline $\begin{array}{l}\text { Resistência à tração } \\
\text { por compressão diametral }\end{array}$ & NBR 7222 (ABNT, 2011) & 3 & 28 \\
\hline $\begin{array}{l}\text { Módulo estático de } \\
\text { elasticidade à compressão }\end{array}$ & NBR 8522 (ABNT, 2008) & 3 & 28 \\
\hline $\begin{array}{l}\text { Absorção de água por } \\
\text { imersão }\end{array}$ & NBR 9778 (ABNT, 2009b) & 3 & 120 \\
\hline Resistividade elétrica & NBR 9204 (ABNT, 2012) & 3 & 132 \\
\hline $\begin{array}{l}\text { Profundidade de } \\
\text { carbonatação }\end{array}$ & $\begin{array}{l}\text { E 391 (LABORATÓRIO..., 1993) e } \\
\text { CPC-18 (INTERNATIONAL..., 1988) }\end{array}$ & 3 & 28 \\
\hline
\end{tabular}

Fonte: ABNT (1998, 2018, 2011, 2008, 2009b, 2012), Laboratório Nacional de Engenharia Civil (1993) e International Union of Laboratories and Experts in Construction Materials, Systems and Structures (1988).

\section{Resultados e discussões}

\section{Caracterização e análise dos agregados graúdos}

A Figura 3 apresenta as curvas granulométricas dos agregados graúdos. O diâmetro máximo característico encontrado é de $19 \mathrm{~mm}$ para os três tipos de AR, já o do AN tem valor de $25 \mathrm{~mm}$. O valor do módulo de finura foi de 4,57 para o AN, de 4,32 para o ARC, de 4,29 para o ARM e de 4,27 para o ARV. Pela distribuição granulométrica, observa-se que todos os agregados graúdos se classificam como Brita 1 , de acordo com a NBR 7211 (ABNT, 2009a).

A Tabela 4 contém os resultados de caracterização dos agregados graúdos.

De acordo com a Tabela 4, é possível perceber que as massas específicas do AN são sempre maiores que as dos AR, sendo a diferença mais acentuada na massa específica aparente, onde a medida do AN foi $44,5 \%$ maior que a do ARV. Essa tendência é confirmada por diversos trabalhos, onde os agregados provenientes de RCD apresentam menores massas específicas em comparação ao AN (ANGULO et al., 2009; NAGATAKI et al., 2004).

O AN apresenta massa unitária de 23 a 41\% maior que os AR. Além disso, os valores de índice de vazios são maiores nos AR, tendo o ARV a menor massa unitária e o maior índice de vazios entre os agregados.

Com relação à absorção e à porosidade, há uma grande diferença entre os três tipos de agregados. A diferença entre a porosidade dos AN e os ARV chega a 330\%, já a absorção dos ARV é $471 \%$ maior quando comparados aos AN. Resultados como esses deveriam ser levados em conta nas dosagens, uma vez que têm grande influência na mistura e adensamento dos concretos reciclados. Assim como no presente estudo, Kou, Poon e Etxeberria (2011) relatam maiores absorções de água dos AR em comparação aos AN. Ferreira, Barra e de Brito (2011) indicam valores de absorção 4,6\% maiores nos AR em comparação aos AN.

Os resultados apontam que a perda de material por abrasão é consideravelmente menor nos AN. Os AR tiveram desempenho bastante semelhante entre si, ou seja, embora a porosidade influencie tanto na resistência à abrasão quanto na absorção de água, os impactos são muito mais relevantes nesta do que naquela.

Acredita-se que muito da resistência à abrasão apresentada pelos ARV se deva ao fato de que é parcialmente constituída por cerâmicas de piso e revestimento, que são fabricadas com o propósito de apresentarem boa resistência nesse quesito.

Sabe-se, por norma, que o limite para o índice de perda à abrasão é de 50\% de material. Com isso, os AR estão muito próximos desse limite, sendo o ARC reprovado e o ARM e o ARV aprovados por margem mínima. O AN está dentro dos padrões exigidos.

A Figura 4 apresenta as curvas de absorção de água em 30 minutos dos AR.

184 Salles, P. V.; Gomes, C. L.; Poggiali, F. S. J.; Rodrigues, C. de S. 
Figura 3 - Curvas granulométricas do agregado graúdo

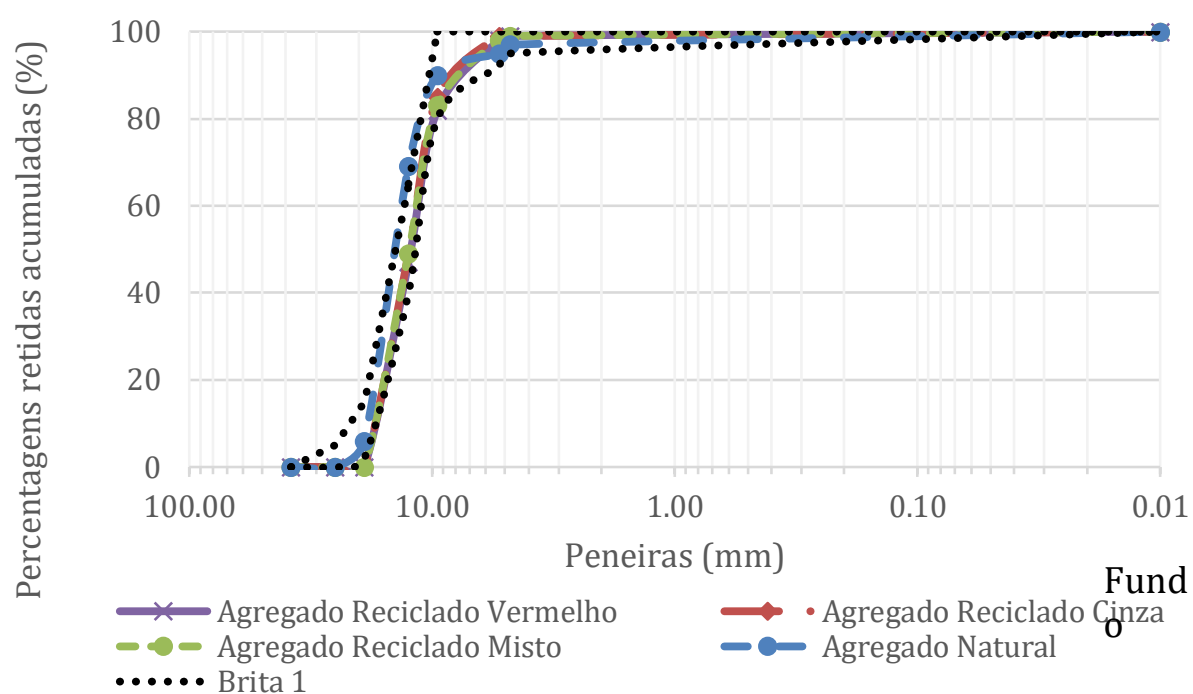

Tabela 4 - Propriedades dos agregados graúdos

\begin{tabular}{c|c|c|c|c|c|c|c|c}
\hline Agregado & $\mathbf{d}\left(\mathbf{g} / \mathbf{c m}^{\mathbf{3}}\right)$ & $\mathbf{d}_{\mathbf{a}}\left(\mathbf{g} / \mathbf{c m}^{\mathbf{3}}\right)$ & $\mathbf{d}_{\mathbf{s}}\left(\mathbf{g} / \mathbf{c m}^{\mathbf{3}}\right)$ & $\boldsymbol{\rho}_{\mathbf{a p}}\left(\mathbf{g} / \mathbf{c m}^{\mathbf{3}}\right)$ & $\mathbf{A}(\boldsymbol{\%})$ & $\mathbf{P}(\boldsymbol{\%})$ & $\mathbf{P}_{\mathbf{L A}}(\boldsymbol{\%})$ & $\mathbf{E}_{\mathbf{v}}(\boldsymbol{\%})$ \\
\hline AN & 2,66 & 2,63 & 2,64 & 1,44 & 0,33 & 0,86 & 22,00 & 45,67 \\
ARC & 2,55 & 2,12 & 2,29 & 1,18 & 7,88 & 16,71 & 50,80 & 53,73 \\
ARM & 2,55 & 2,03 & 2,22 & 1,12 & 10,65 & 21,67 & 49,90 & 55,97 \\
ARV & 2,54 & 1,82 & 2,10 & 1,03 & 15,66 & 28,46 & 48,40 & 59,49 \\
\hline
\end{tabular}

Nota: Legenda:

d: massa específica do agregado seco;

$\mathrm{d}_{\mathrm{a}}$ : massa específica aparente;

$\mathrm{d}_{\mathrm{s}}$ : massa específica do agregado na condição saturado superfície seca;

$\rho_{\text {ap: }}$ massa unitária do agregado;

A: absorção de água;

$P$ : porosidade;

PLA: índice Los Angeles de perda por abrasão;

$\mathrm{E}_{\mathrm{v}}$ : índice de volume de vazios nos agregados;

NA: agregado natural;

ARC: agregado reciclado cinza;

ARM: agregado reciclado misto; e

ARV: agregado reciclado vermelho.

Figura 4 - Curva de saturação em 30 minutos

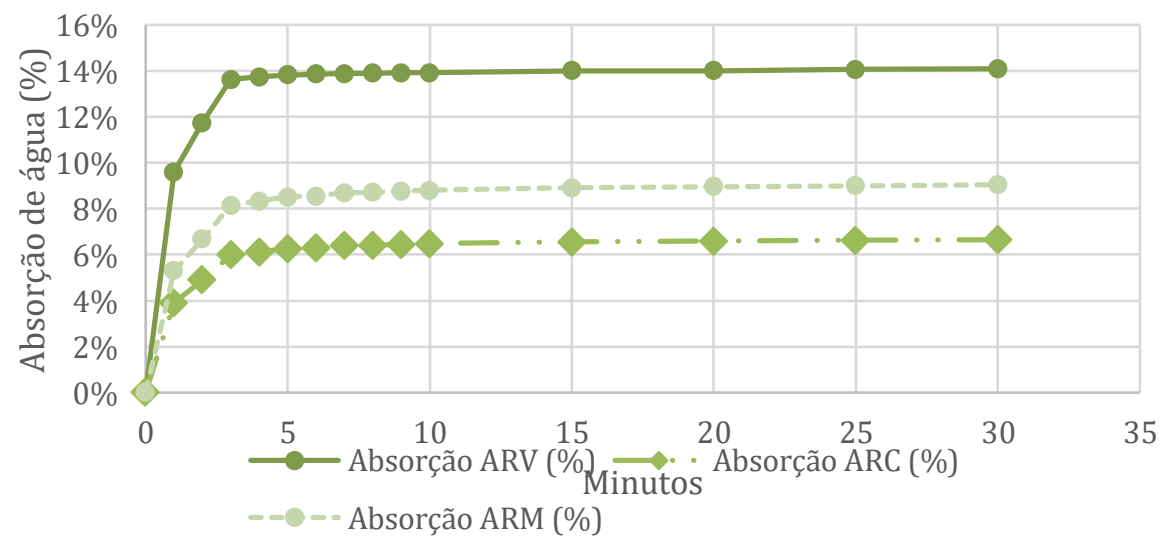

Nota: Legenda:

ARV: agregado reciclado vermelho;

ARC: agregado reciclado cinza; e

ARM: agregado reciclado misto. 
Percebe-se que a maior absorção de água (mais de $90 \%$ da absorção final) ocorre nos primeiros cinco minutos do ensaio, novamente a absorção dos ARV é maior que a dos demais AR. É importante ressaltar a importância desses dados na mistura, lançamento e adensamento desses concretos. Concretos com presença AR tendem a apresentar problemas nessas fases, sendo menos trabalháveis e necessitando de maior energia de adensamento para se adequarem.

\section{Caracterização e análise dos concretos}

\section{Consistência pelo abatimento do tronco de cone}

Os resultados do slump test, apresentados na Figura 5, indicam a trabalhabilidade dos concretos fabricados.

Pode-se perceber que a trabalhabilidade do concreto está ligada ao teor de AR presente na mistura. Quanto maior a quantidade de AR, independentemente do tipo de resíduo, menor o abatimento do tronco de cone. Essa falta de trabalhabilidade pode resultar em coesão, hidratação e homogeneidade insuficientes. Entendese que esses problemas sejam mais evidentes no traço com 100\% ARV, como fica demonstrado nos tópicos a seguir, o desempenho desse concreto é sempre inferior aos demais. Esses resultados são corroborados por Matias et al. (2014), Zhang e Zong (2013), entre outros, que também indicam perda de trabalhabilidade com uso de AR.

A perda de trabalhabilidade está ligada à maior absorção por parte dos AR. É importante notar que os AR utilizados estavam secos e que não passaram por um processo de pré-saturação. A prática usual ao se utilizar $\mathrm{AR}$ é corrigir o fator $\mathrm{A} / \mathrm{C}$ do traço, no entanto, neste estudo isso não foi feito, pois objetivou-se simplificar a metodologia de sua utilização.

Com a utilização de 1\% de SP-II R, o CR apresenta, em média, $240 \mathrm{~mm}$ de abatimento (valor excessivo, sendo que para os outros ensaios foi utilizado o CR com $0,6 \%$ de SP-II), enquanto os concretos $50 \% \mathrm{ARV}$, $100 \%$ ARC, 100\% ARM e 100\% ARV apresentam $0 \mathrm{~mm}$ de abatimento. Observa-se, também, que, quanto maior é a absorção de determinado tipo de agregado, maior é a influência negativa deste sobre a trabalhabilidade.

Com isso em vista, entende-se que grandes quantidades de agregados de RCD - principalmente dos mais absorventes - podem causar graves problemas na sua utilização, não sendo suficiente as quantidades de SP utilizadas, demandando a utilização de AR pré-saturados e/ou maior quantidade de aditivos.

\section{Figura 5 - Abatimento do tronco de cone}

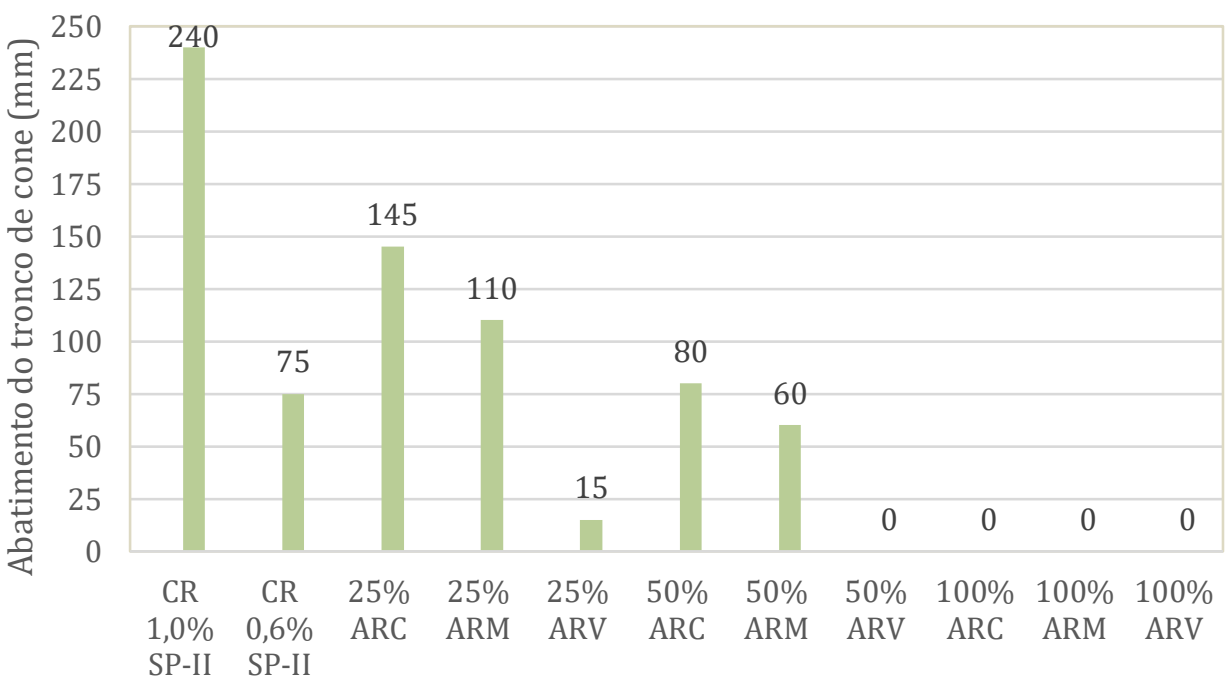

Formulação

Nota: Legenda:

CR: concreto de referência;

SP-II: superplastificante tipo II;

ARC: agregado reciclado cinza;

ARM: agregado reciclado misto; e

ARV: agregado reciclado vermelho.

186 Salles, P. V.; Gomes, C. L.; Poggiali, F. S. J.; Rodrigues, C. de S. 
Compreende-se que, nas condições desse estudo, os concretos reciclados com 25 e $50 \%$ de ARC e ARM, apresentam trabalhabilidade mínima para que possam ser utilizados em estruturas convencionais. Outras possibilidades de aditivos e alterações no traço podem fazer com que outros teores e tipos de substituição do AN por AR se viabilizem.

\section{Resistência à compressão axial}

A Figura 6 mostra os valores de resistência à compressão aos 28 dias dos concretos.

Os resultados aos 28 dias apontam um desempenho inferior dos concretos com AR em comparação ao CR. Com o uso do AR há uma perda mínima de aproximadamente 10\% (50\% ARC) na resistência à compressão e uma perda máxima de aproximadamente $81 \%$ (100\% ARV). Os concretos com $25 \%$ de AR, $50 \%$ ARC e ARM e 100\% ARC apresentam perdas em torno de 15\% da resistência à compressão. Sendo assim, infere-se que ajustes e adequações no traço dessas substituições seriam suficientes para corrigir essa perda de resistência. Também se infere que a falta de trabalhabilidade de algumas misturas tenha influenciado negativamente o desempenho de alguns concretos, principalmente o $100 \% \mathrm{ARV}$.

A tendência apresentada é corroborada por diversos estudos, onde a adição de AR prejudica o desempenho do concreto. Etxeberria et al. (2007), mantendo constante a relação A/C e utilizando ARC, relatam perdas de resistência de 20 a 25\% com substituições de 25, 50 e 100\% do AN. Empregando teores de substituição de 20, 50 e 100\%, Kou e Poon (2012) também relatam perdas de resistência a compressão. Os concretos fabricados com mesma quantidade de água e cimento têm perda de resistência proporcional ao teor de substituição.

Infere-se que, até determinado ponto, a diminuição do fator $\mathrm{A} / \mathrm{C}$ efetivo, causada pela absorção dos agregados de RCD de parte da água de amassamento, seja benéfica aos concretos reciclados, aumentando sua resistência à compressão e compensando a fragilidade dos AR. A partir de determinado fator de substituição (50\% ARV, 100\% ARM), as características negativas dos AR (baixa resistência, alta porosidade, baixa densidade etc.) sobrepõem-se à diminuição do fator $\mathrm{A} / \mathrm{C}$.

Entre os concretos reciclados apresentados, entende-se que os $25 \%$ de AR, 50\% ARC e ARM e $100 \%$ ARC podem ser utilizados sem grandes perdas (entre 10 e 20\%) no que diz respeito à resistência à compressão, em comparação com o CR.

Figura 6 - Resistência média à compressão aos 28 dias

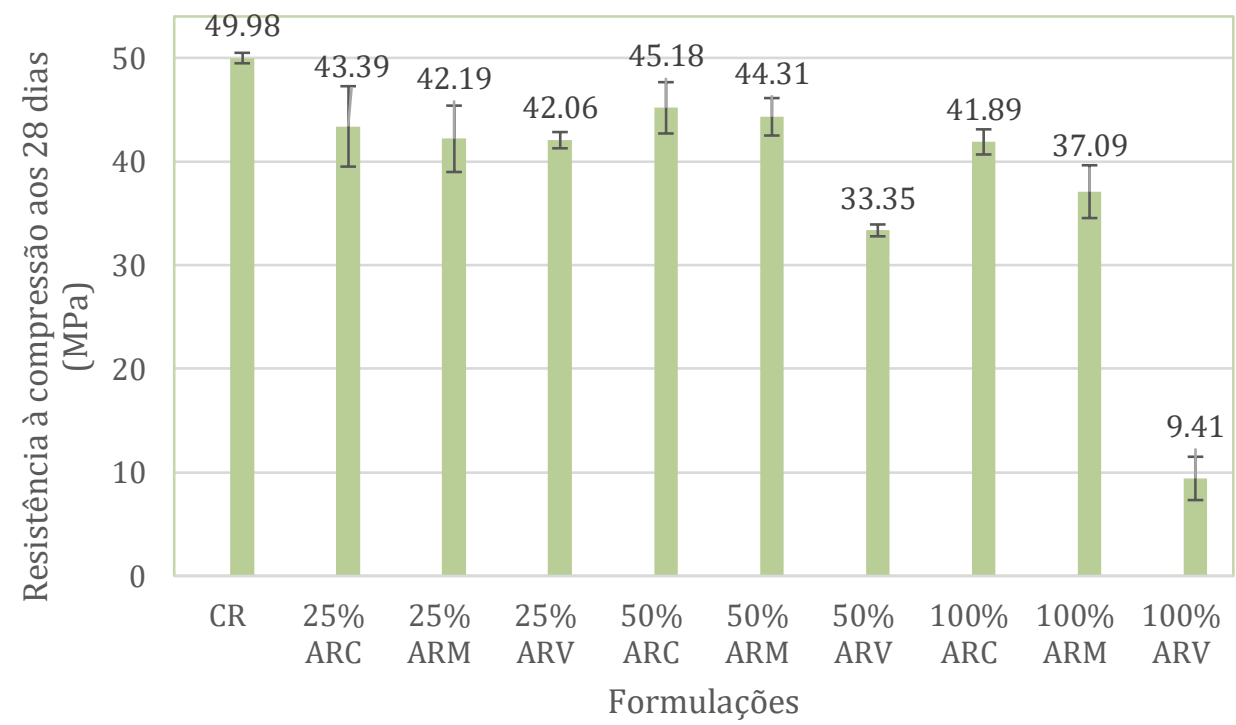

Nota: Legenda:

CR: concreto de referência;

ARC: agregado reciclado cinza;

ARM: agregado reciclado misto; e

ARV: agregado reciclado vermelho. 
Outro ponto importante a se notar é o desempenho similar dos concretos com a presença de ARC e ARM, o que leva a inferir que a segregação não seria necessária, tendo em vista as proporções dos resíduos que compõem o ARM nesse estudo. Essa constatação vai contra as recomendações da International Union of Laboratories and Experts in Construction Materials, Systems and Structures, na recomendação TC 121, do Laboratório Nacional de Engenharia Civil, em sua normativa E471, e da NBR 15116 (ABNT, 2004), que indicam a segregação dos resíduos para sua utilização em concretos com classes de resistências mais altas (acima de $20 \mathrm{MPa}$ ) e teores máximos de resíduos vermelhos iguais a 10\% em resíduos de maior qualidade (ABNT, 2004; LABORATÓRIO..., 2009; INTERNATIONAL..., 1994). Angulo et al. (2009) também recomendam a separação das frações constituintes, uma vez que agregados menos densos originam concretos menos resistentes. Já Hendriks, Nijkerk e van Koppen (2007) entendem que a separação deva ser realizada ainda em campo, no intuito de aumentar a qualidade dos agregados provenientes de RCD. Contudo, os resultados deste estudo apontam que a separação de RCD não é algo essencial no contexto apresentado.

\section{Resistência à tração}

Os resultados dos ensaios de compressão diametral dos concretos forneceram os dados expostos na Figura 7.

Os resultados indicam que o acréscimo de ARC e de ARM aos concretos não comprometem as resistências à tração. Levando em conta o desvio padrão, todas as misturas, exceto a 100\% ARV, apresentam valores próximos - inclusive, o valor médio de resistência à tração do concreto $25 \%$ ARM é maior que o do CR. Novamente, a utilização de $100 \%$ ARV prejudica o desempenho dos concretos.

Etxeberria et al. (2007) relatam aprimoramento do desempenho de tração de concretos com adição de ARC. Os autores apontam como motivo a efetividade da nova ZTI do concreto reciclado. Em outra pesquisa, os autores expõem resultados de concretos com AR que atingem resistências à tração iguais ou maiores do que o concreto fabricado com AN. É relatado que o AR melhorou a microestrutura da zona de transição interfacial e aumentou a resistência da ligação entre a nova pasta de cimento e os agregados antigos (KOU; POON; ETXEBERRIA, 2011).

Nesse caso, o mecanismo responsável pela melhoria poderia ser o AR que, absorvendo uma certa quantidade de água livre, diminui a relação A/C inicial na ZTI. Com isso, é possível que produtos hidratação preencham gradualmente a região, melhorando efetivamente a ligação interfacial entre os agregados e a matriz cimentícia (POON; SHUI; LAM, 2004).

\section{Módulo estático de elasticidade}

Os resultados do módulo estático de elasticidade médio, obtidos aos 28 dias, são apresentados na Figura 8.

\section{Figura 7 - Resistência média à tração aos 28 dias}

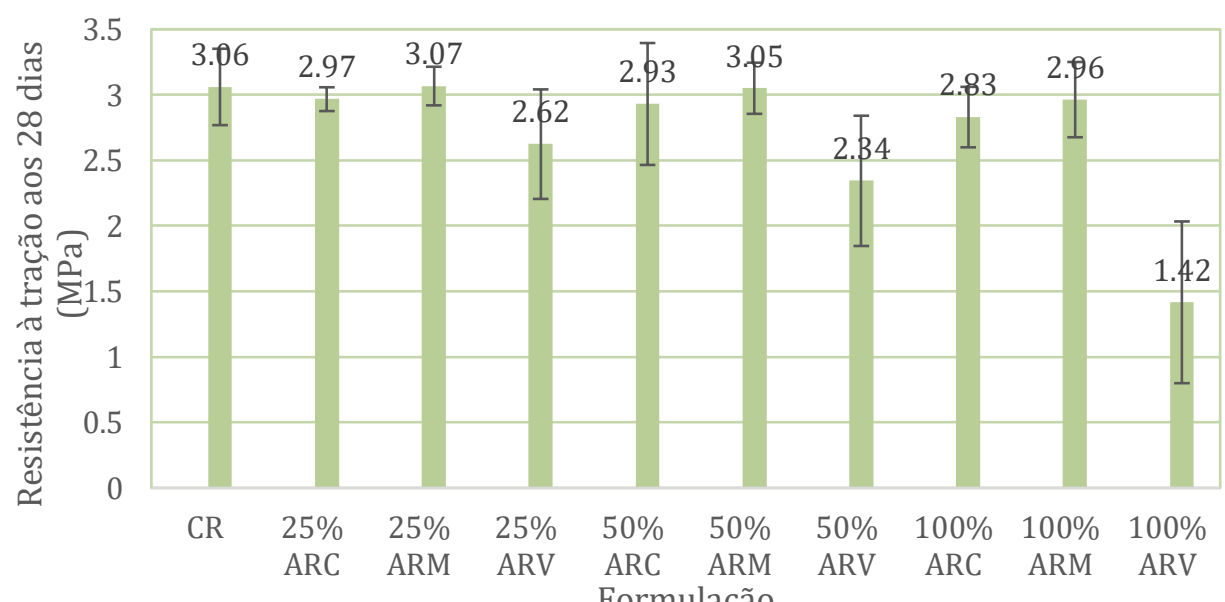

Nota: Legenda:

CR: concreto de referência;

ARC: agregado reciclado cinza;

ARM: agregado reciclado misto; e

ARV: agregado reciclado vermelho.

188 Salles, P. V.; Gomes, C. L.; Poggiali, F. S. J.; Rodrigues, C. de S. 
Figura 8 - Módulo estático de elasticidade médio aos 28 dias

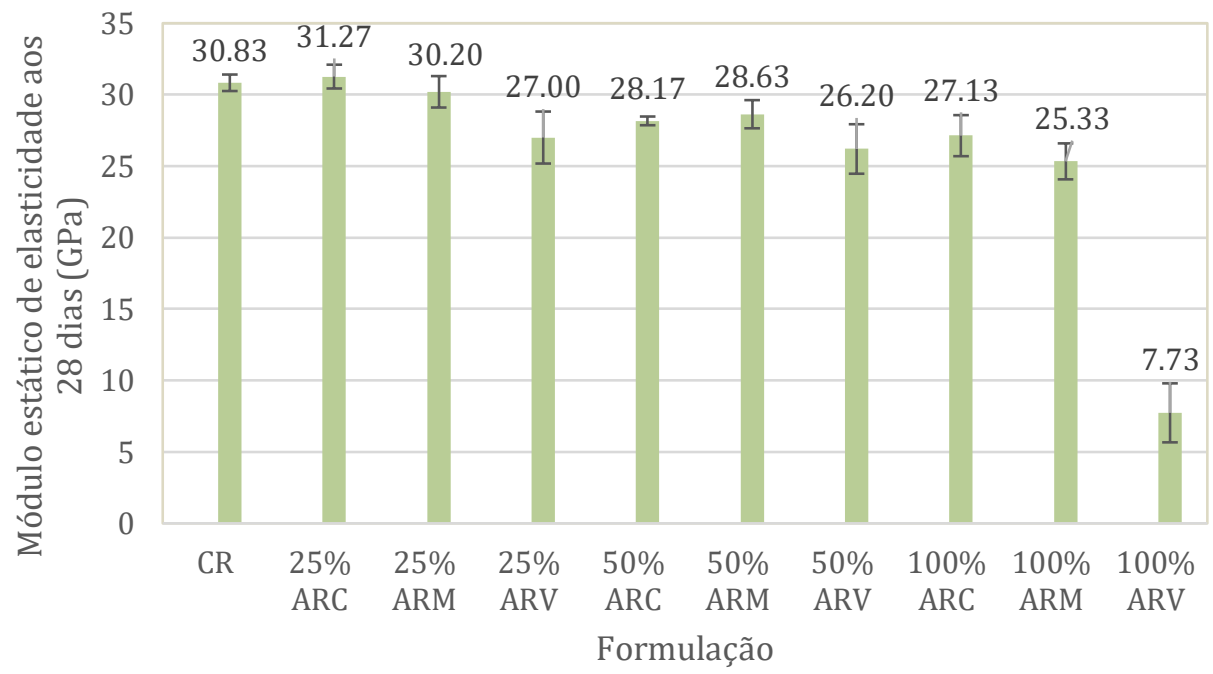

Nota: Legenda:

CR: concreto de referência;

ARC: agregado reciclado cinza;

ARM: agregado reciclado misto; e

ARV: agregado reciclado vermelho.

A análise dos dados indica que o teor de adição e o tipo de resíduos usado influenciam nos valores obtidos nos ensaios. Inicialmente, é importante notar que apenas duas formulações com AR atingiram valores similares ao CR, levando em consideração o desvio padrão, o $25 \% \mathrm{ARC}$ e o $25 \% \mathrm{ARM}$, tendo o primeiro um valor médio pouco superior à referência. As demais formulações obtiveram valores inferiores no módulo de elasticidade. É notório o fato de que o módulo de elasticidade acompanha as tendências apresentadas pela resistência à compressão, o que pode ser observado na comparação dos resultados das Figuras 6 e 8.

Ao avaliar a influência do teor de substituição (levando em conta determinado tipo de resíduo), percebe-se que quanto maior é a quantidade de agregados de RCD na mistura, menor são os valores médios de módulo de elasticidade obtidos. Analisando o tipo de agregado utilizado é possível observar que o ARC tem um desempenho superior entre os AR, seguido pelo ARM e, por último, pelo ARV (exceto na substituição de $50 \%$ onde o valor médio para o ARM é ligeiramente maior). Acredita-se que o menor módulo de elasticidade dos AR tenha influenciado o desempenho dos concretos nesse quesito, diminuindo os resultados dos concretos reciclados. Ao utilizar materiais com um módulo de elasticidade menor que a rocha gnaisse são obtidos concretos com características compatíveis.

Apesar das considerações acerca das quedas nos valores do módulo de elasticidade, nota-se que, na maioria dos traços (em seis deles), as perdas apresentadas são de, no máximo, 20\% (resultados proporcionais à resistência à compressão) com relação ao $\mathrm{CR}$. Além disso, novamente, percebe-se resultados próximos entre os concretos com AR. Isso se deve a uma melhora na microestrutura da matriz, que, ao ter seu fator $\mathrm{A} / \mathrm{C}$ reduzido, compensa parcialmente o baixo módulo de elasticidade dos AR. Isso indica que o uso de AR não afeta massivamente o módulo de elasticidade. Infere-se que essas reduções de até $20 \%$ no módulo de elasticidade podem ser reduzidas com correções nos traços.

\section{Absorção de água}

A Figura 9 mostra os resultados alcançados no quesito absorção de água do concreto aos 28 dias.

A introdução e o aumento no fator de substituição dos AN causam, de forma geral, um aumento na absorção de água das formulações. Essa tendência pode ser relacionada aos dados apresentados na Tabela 4; quanto menor é a absorção média do agregado, menor é a absorção média do concreto fabricado com esse agregado. Com relação aos agregados, o ARV apresenta absorção 471\% maior que o AN; já no concreto, a absorção da mistura $100 \%$ ARV equivale a $291 \%$ do $C R$. 
Figura 9 - Absorção de água média aos 28 dias

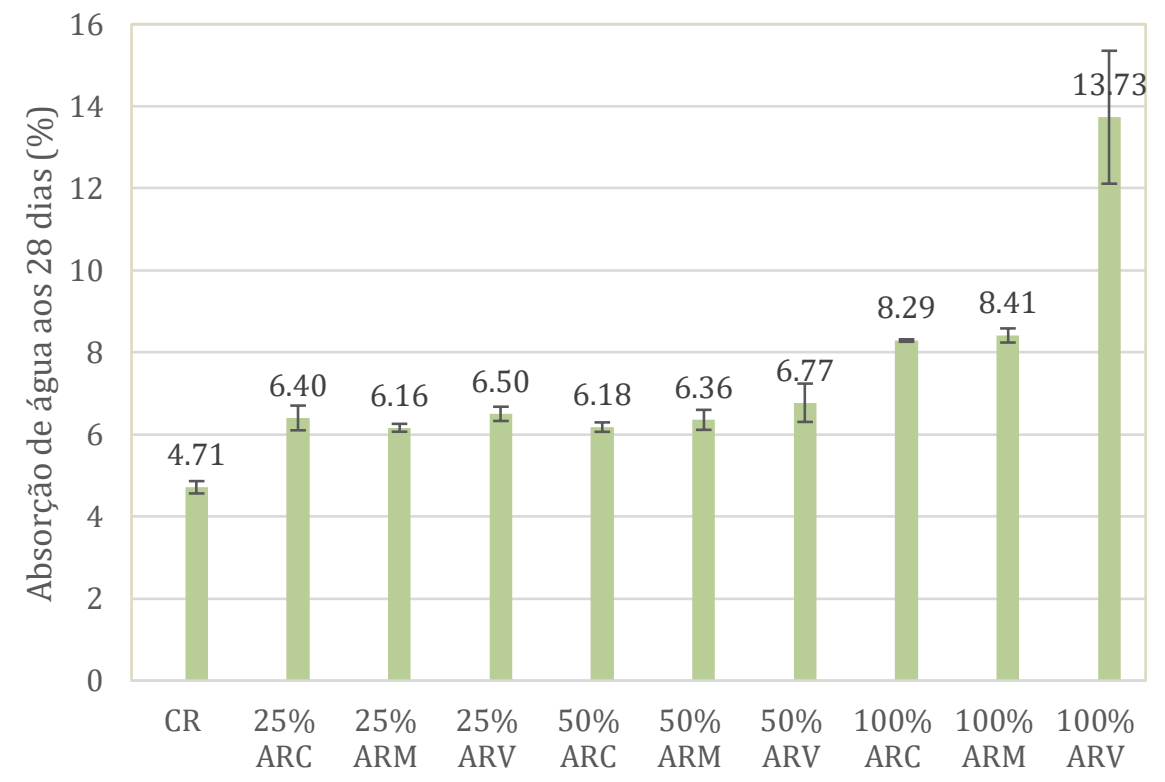

Formulação

Nota: Legenda:

CR: concreto de referência;

ARC: agregado reciclado cinza;

ARM: agregado reciclado misto; e

ARV: agregado reciclado vermelho.

$\mathrm{Na}$ absorção de água, não há concreto similar à referência, fabricada apenas com brita gnaisse. Infere-se que isso se deva às diferenças apresentadas pelos $\mathrm{AR}$ em comparação aos $\mathrm{AN}$, onde os $\mathrm{AR}$ apresentam maior absorção de água e índice de vazios, características que são levadas para os concretos reciclados.

\section{Resistividade elétrica}

Os resultados expostos na Figura 10 indicam grande variabilidade entre as formulações e, em alguns casos, um desvio padrão elevado, o que dificulta a análise sobre a qualidade dos concretos fabricados em relação à corrosão de armaduras. Não é possível perceber uma tendência de aumento ou de diminuição de resistividade elétrica com a variação do teor de substituição do AN por AR. Também não é possível afirmar qual tipo de resíduos obteve melhor desempenho.

Apesar da variabilidade dos resultados, todas as formulações foram classificadas na mesma faixa de risco de corrosão da armadura de aço. Os concretos moldados foram classificados tendo baixa resistência à corrosão (BAROGHEL-BOUNY et al., 2011).

Baroghel-Bouny et al. (2011) indicam que concretos fabricados com 20 e 25\% de resíduos cerâmicos obtiveram classificação de baixa resistência à corrosão das armaduras (mesma classificação de todos os concretos desta pesquisa), enquanto o CR obteve classificação de muito baixa resistência. De acordo com os autores, a não condutividade inata das cerâmicas refreou o fato de elas serem mais porosas do que os AN, conferindo maior resistividade.

\section{Carbonatação}

De maneira geral, os dados expostos na Figura 11 demonstram que a adição de AR melhora a resistência ao avanço da frente de carbonatação nos concretos fabricados, independentemente do tipo de RCD utilizado, e em grau proporcional à quantidade de $\mathrm{AN}$ substituído por $\mathrm{AR}$. 
Figura 10 - Resistividade elétrica média aos 120 dias

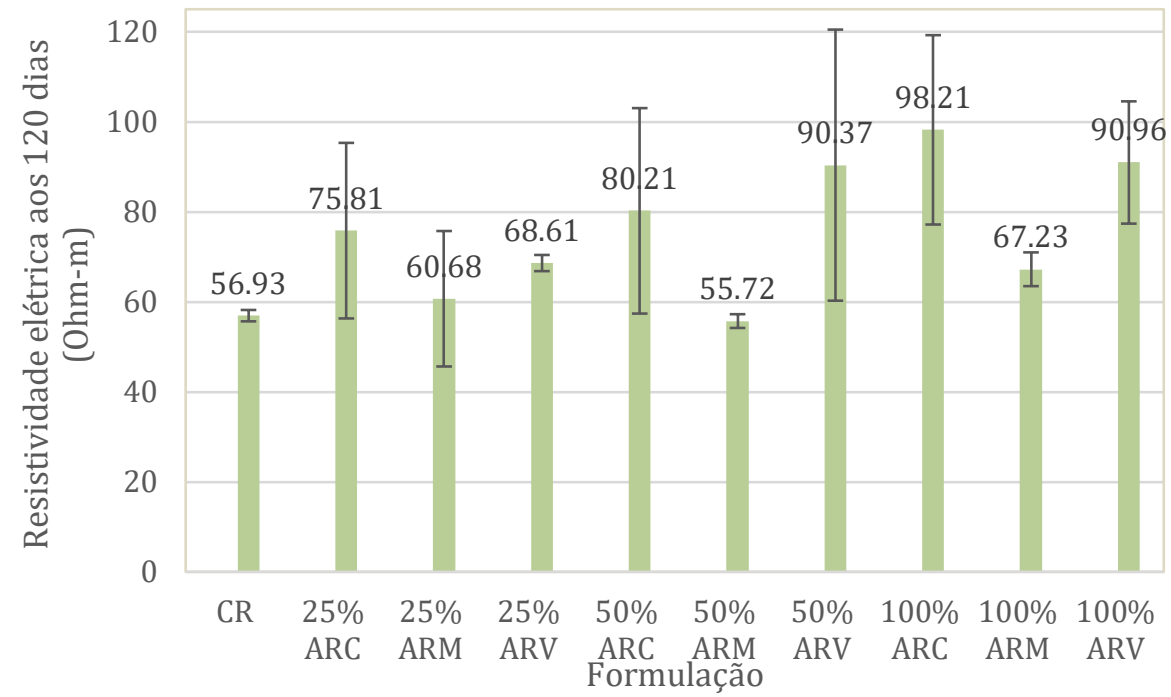

Nota: Legenda:

CR: concreto de referência;

ARC: agregado reciclado cinza;

ARM: agregado reciclado misto; e

ARV: agregado reciclado vermelho.

Figura 11 - Profundidade média da frente de carbonatação aos 90 dias de exposição

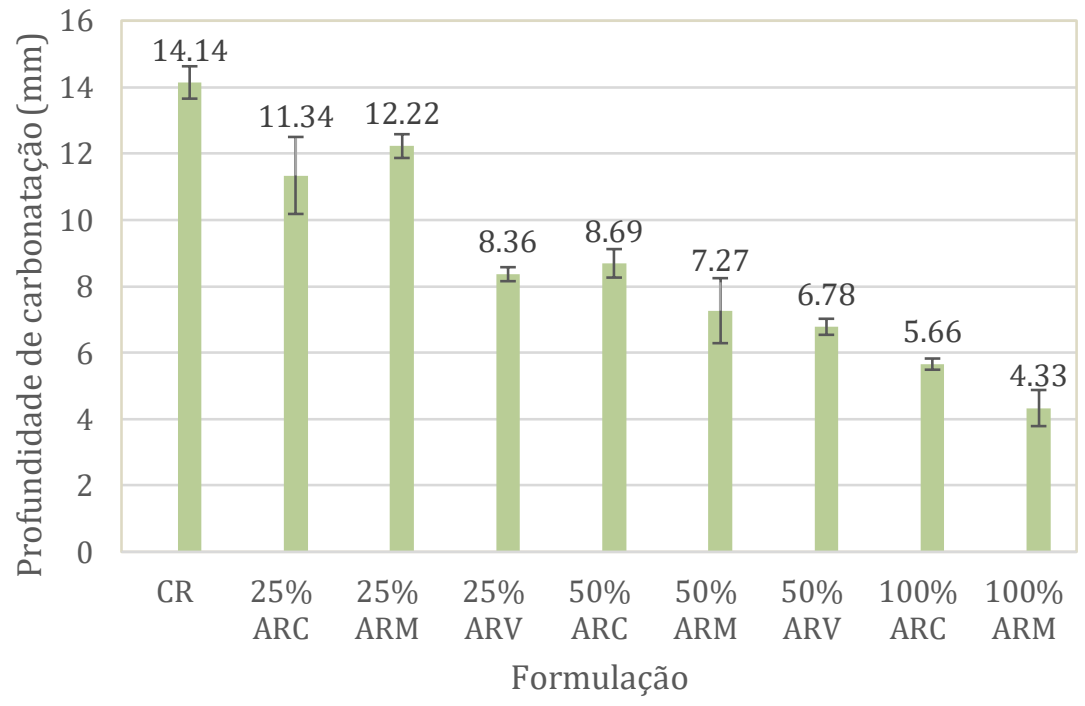

Nota: Legenda:

CR: concreto de referência;

ARC: agregado reciclado cinza;

ARM: agregado reciclado misto; e

ARV: agregado reciclado vermelho.

Tem-se o concreto com $100 \%$ AN com a maior profundidade de carbonatação, que se apresenta $326 \%$ maior que a profundidade de carbonatação do concreto 100\% ARM, o traço com menor avanço da frente. O desempenho do ARV (para substituições de 25 e 50\%) é superior aos dos outros AR, e o teor de substituição do AN é inversamente proporcional à profundidade de carbonatação. Nota-se a ausência de dados da formulação 100\% ARV. Essa formulação apresentou dificuldades de adensamento, o que resultou em um concreto muito poroso. Sendo assim, os ensaios de carbonatação acelerada desse concreto resultaram na carbonatação total dos CP. 
Com base nos dados apresentados, infere-se que o avanço da frente de carbonatação possa estar ligada ao fator A/C efetivo da formulação e que a adição de AR é benéfica nesse quesito. Os AR apresentam absorção de água muito elevada em relação aos AN. Sendo assim, no momento da moldagem, absorvem água de amassamento da mistura, com isso o fator $\mathrm{A} / \mathrm{C}$ dos concretos reciclados é menor. Quanto maior o teor de substituição e mais absorvente o resíduo (ARV), menor o fator $\mathrm{A} / \mathrm{C}$ efetivo e, de acordo com os resultados da carbonatação acelerada, menor o avanço da frente de carbonatação. Os efeitos da redução da relação A/C efetiva são mais perceptíveis na resistência à carbonatação, contudo, infere-se que esse fato tenha efeitos no desempenho geral dos traços, aproximando o desempenho dos concretos com AR do CR.

Outra possível explicação sobre a melhoria na resistência à carbonatação dos traços com AR é a presença de álcalis extras na mistura, que seriam provenientes de partículas cimentícias introduzidas no concreto por meio dos RCD e que potencialmente poderiam elevar a reserva alcalina dos traços (GOMES, 2019; LEVY; HELENE, 2004).

Resultados similares aos apresentados são expostos por Thomas et al. (2012), quem apontam que, no caso em que se mantém a resistência à compressão constante, os concretos com AR levam pequena vantagem sobre os CR no quesito resistência ao avanço da frente de carbonatação. Isso pode ser explicado pelo fator A/C dos concretos com AR ser menor em tais circunstâncias. Corinaldesi e Moriconi (2009) apontam que, com relação à carbonatação, os resultados do ensaio foram fortemente dominados pela relação $\mathrm{A} / \mathrm{C}$. $\mathrm{O}$ traço com menor quantidade de água e $100 \%$ de AR apresentou melhores resultados com relação à carbonatação (excetua-se o 100\% ARV).

De maneira geral, entende-se que a diminuição do fator $\mathrm{A} / \mathrm{C}$ efetivo, pela absorção de água dos $\mathrm{AR}$, permite que os concretos reciclados tenham melhores resultados no quesito resistência ao avanço da frente de carbonatação, conforme exposto nos resultados apresentados.

\section{Conclusões}

Tendo em vista a necessidade de segregação dos RCD para utilização como agregados graúdos em concretos estruturais, conclui-se não ser imprescindível sua separação. O ARM (nas proporções de 83,94\% ARC e $16,06 \%$ ARV) não carece ser segregado, uma vez que os concretos fabricados com esse tipo de resíduo apresentam características próximas ou superiores às formulações que utilizam apenas ARC.

Também foi constatado que essas substituições influenciam no desempenho dos concretos estruturais. Entre os principais efeitos do uso de RCD como agregado graúdo, podem ser mencionadas as conclusões apresentadas a seguir.

A trabalhabilidade de todos os traços foi afetada pela adição de resíduos. Quanto maior a quantidade de AR e quanto mais absorventes esses resíduos, menor a trabalhabilidade dos concretos fabricados.

A resistência à compressão foi prejudicada pela adição de agregado proveniente de RCD à mistura. Os valores de compressão obtidos pelos ensaios de $\mathrm{CP}$ cilíndricos apontam como pior desempenho os traços com ARV. Contudo, aos 28 dias, formulações com 25\% de ARC, ARM e ARV, com 50\% de ARC e ARM e com $100 \%$ de ARC apresentam perdas de resistência próximas a 15\%. Acredita-se que ajustes e correções no traço possam reverter essa perda.

Com relação à resistência à tração por compressão diametral, observou-se que o uso de ARC e ARM não influenciaram nos valores obtidos, independentemente do teor de substituição, o que se explica pela melhora da ZTI em concretos reciclados.

Os resultados dos ensaios de módulo de elasticidade indicam diminuição nos valores encontrados proporcionais ao grau de substituição dos agregados naturais. Essa perda é mais intensa no caso de utilização de agregados cerâmicos (ARV). Contudo, nota-se que, na maioria das formulações (em seis delas), as perdas apresentadas são de no máximo $20 \%$ com relação ao CR.

Os ensaios de absorção por imersão indicam que a adição de AR prejudica o desempenho dos concretos fabricados. Entre os AR, o que tem maior influência negativa sobre os concretos é o ARV, uma vez que resulta em um concreto com maior absorção.

Os resultados de resistividade elétrica indicam não haver efeitos da substituição dos AN por AR. Todos os concretos - inclusive o referência - foram avaliados com baixa resistência à corrosão das armaduras.

192 Salles, P. V.; Gomes, C. L.; Poggiali, F. S. J.; Rodrigues, C. de S. 
Os concretos reciclados apresentam maior resistência ao avanço da frente de carbonatação. Quanto maior a quantidade de resíduos na mistura, menor a carbonatação (com exceção da formulação 100\% ARV). Inferese que esse resultado se deva à diminuição do fator $\mathrm{A} / \mathrm{C}$ efetivo com a utilização de $\mathrm{AR}$.

Diante das análises efetuadas, é possível concluir que as formulações com $25 \%$ e $50 \%$ de ARC e de ARM e com $25 \%$ de ARV são as mais apropriadas para serem utilizadas na fabricação de concretos estruturais. Essa constatação se baseia no fato de que essas formulações apresentam pouca diferença de desempenho em relação à formulação de referência com $100 \% \mathrm{AN}$. Levando em conta os ganhos ambientais (destinação final adequada dos resíduos e não extração de recursos não renováveis) essas formulações se tornam vantajosas.

Como sugestão para trabalhos futuros, indica-se a avaliação de métodos para compensar a elevada absorção dos AR, a utilização de métodos de dosagem específicos para o uso de AR e o aprofundamento no estudo da carbonatação e resistividade elétrica nos concretos com agregados provenientes de RCD.

\section{Referências}

AGRELA, F. et al. Limiting properties in the characterisation of mixed recycled aggregates for use in the manufacture of concrete. Construction and Building Materials, v. 25, p. 3950-3955, 2011.

ALIABDO, A. A.; ABD-ELMOATY, A. E. M.; HASSAN, H. H. Utilization of crushed clay brick in concrete industry. Alexandria Engineering Journal, v. 53, n. 1, p. 151-168, 2014.

ANGULO, S. C. et al. On the classification of mixed construction and demolition waste aggregate by porosity and its impact on the mechanical performance of concrete. Materials and Structures, v. 43, p. 519-528, 2009.

ASSOCIAÇÃO BRASILEIRA DE NORMAS TÉCNICAS. NBR 15116: agregados reciclados de resíduos sólidos da construção civil: utilização em pavimentação e preparo de concreto sem função estrutural: requisitos. Rio de Janeiro, 2004.

ASSOCIAÇÃO BRASILEIRA DE NORMAS TÉCNICAS. NBR 5738: concreto: procedimento para moldagem e cura de corpos-de-prova. Rio de Janeiro, 2003a.

ASSOCIAÇÃO BRASILEIRA DE NORMAS TÉCNICAS. NBR 5739: concreto: ensaios de compressão de corpos-de-prova cilíndricos. Rio de Janeiro, 2018.

ASSOCIAÇÃO BRASILEIRA DE NORMAS TÉCNICAS. NBR 7211: agregados para concreto: especificação. Rio de Janeiro, 2009a.

ASSOCIAÇÃO BRASILEIRA DE NORMAS TÉCNICAS. NBR 7222: concreto e argamassa: determinação da resistência à tração por compressão diametral de corpos de prova cilíndricos. Rio de Janeiro, 2011.

ASSOCIAÇÃO BRASILEIRA DE NORMAS TÉCNICAS. NBR 8522: concreto: determinação do módulo estático de elasticidade à compressão. Rio de Janeiro, 2008.

ASSOCIAÇÃO BRASILEIRA DE NORMAS TÉCNICAS. NBR 9204: concreto endurecido: determinação da resistividade elétrico volumétrica: método de ensaio. Rio de Janeiro, 2012.

ASSOCIAÇÃO BRASILEIRA DE NORMAS TÉCNICAS. NBR 9776: agregados: determinação da massa específica de agregados miúdos por meio do frasco Chapman. Rio de Janeiro, 1987.

ASSOCIAÇÃO BRASILEIRA DE NORMAS TÉCNICAS. NBR 9778: argamassa e concreto endurecidos: determinação da absorção de água por imersão - Índice de vazios e massa específica. Rio de Janeiro, $2009 \mathrm{~b}$.

ASSOCIAÇÃO BRASILEIRA DE NORMAS TÉCNICAS. NBR NM 248: agregados: determinação da composição granulométrica. Rio de Janeiro, 2003b.

ASSOCIAÇÃO BRASILEIRA DE NORMAS TÉCNICAS. NBR NM 45: determinação da massa unitária e do volume de vazios. Rio de Janeiro, 2006.

ASSOCIAÇÃO BRASILEIRA DE NORMAS TÉCNICAS. NBR NM 51: ensaio de abrasão "Los Ángeles". Rio de Janeiro, 2001.

ASSOCIAÇÃO BRASILEIRA DE NORMAS TÉCNICAS. NBR NM 53: agregado graúdo: determinação de massa específica, massa específica aparente e absorção de água. Rio de Janeiro, 2009c.

ASSOCIAÇÃO BRASILEIRA DE NORMAS TÉCNICAS. NBR NM 67: concreto: determinação da consistência pelo abatimento do tronco de cone: procedimento. Rio de Janeiro, 1998. 
BAROGHEL-BOUNY, V. et al. Easy assessment of durability indicators for service life prediction or quality control of concretes with high volumes of supplementary cementitious materials. Cement and Concrete Composites, v. 33, n. 8, p. 832-847, 2011.

BRASIL. Resolução CONAMA No 307, de 5 de julho de 2002, que estabelece diretrizes, critérios e procedimentos para a gestão dos resíduos da construção civil. Brasília, 2002.

CORINALDESI, V.; MORICONI, G. Influence of mineral additions on the performance of $100 \%$ recycled aggregate concrete. Construction and Building Materials, v. 23, n. 8, p. 2869-2876, 2009.

DE BRITO, L.; DOMINGUES DE FIGUEIREDO, A.; JOHN, V. M. Evaluation of the use of crushed returned concrete as recycled aggregate in ready-mix concrete plant. Journal of Building Engineering, v. 31, p. 101408-101422, set. 2020.

DUAN, Z. et al. Rheological properties of mortar containing recycled powders from construction and demolition wastes. Construction and Building Materials, v. 237, p. 117622-117632, mar. 2020a.

DUAN, Z. et al. Study on the essential properties of recycled powders from construction and demolition waste. Journal of Cleaner Production, v. 253, 2020 b.

EGUCHI, K. et al. Application of recycled coarse aggregate by mixture to concrete construction.

Construction and Building Materials, v. 21, n. 7, p. 1542-1551, 2007.

ERCA. Fluxer RMX. Itatiba: [s.n.], 2016. Boletim Técnico.

ETXEBERRIA, M. et al. Influence of amount of recycled coarse aggregates and production process on properties of recycled aggregate concrete. Cement and Concrete Research, v. 37, n. 5, p. 735-742, 2007.

FERREIRA, L.; BARRA, M.; DE BRITO, J. Influence of the pre-saturation of recycled coarse concrete aggregates on concrete properties. Magazine of Concrete Research, v. 63, n. 8, p. 617-627, 2011.

GOMES, C. L. Avaliação mecânica e de durabilidade de concretos fabricados com resíduo de construção e demolição e cinza de casca de arroz. Belo Horizonte, 2019. 60 f. Dissertação (Mestrado em Engenharia Civil) - Centro Federal de Educação Tecnológica de Minas Geriais, Belor Horizonte, 2019.

GOMES, M.; DE BRITO, J.; BRAVO, M. Structural concrete with incorporation of coarse recycled concrete and ceramic aggregates: durability performance. Materials and Structures, v. 42, n. 5, p. $663-$ 675, 2009.

HENDRIKS, C. H.; NIJKERK, A. A.; VAN KOPPEN, A. E. O Ciclo da Contrução. Brasília: Editora Universidade de Brasília, 2007.

HOLCIM. Relatórios de ensaios de cimento. Belo Horizonte, 2017.

INTERNATIONAL UNION OF LABORATORIES AND EXPERTS IN CONSTRUCTION MATERIALS, SYSTEMS AND STRUCTURES. CPC-18: measurement of hardened concrete carbonation depth. Paris, 1988.

INTERNATIONAL UNION OF LABORATORIES AND EXPERTS IN CONSTRUCTION MATERIALS, SYSTEMS AND STRUCTURES. Recommendation I2I-DRG: guidance for demolition and reuse of concrete and masonry. Specifications for concrete with recycled aggregates. Materials and Structures, v. 27, p. 557-559, 1994

KOU, S. C.; POON, C. S. Long-term mechanical and durability properties of recycled aggregate concrete prepared with the incorporation of fly ash. Cement and Concrete Composites, v. 37, n. 1, p. 12-19, 2012

KOU, S. C.; POON, C. S.; ETXEBERRIA, M. Influence of recycled aggregates on long term mechanical properties and pore size distribution of concrete. Cement and Concrete Composites, v. 33, n. 2, p. 286 $291,2011$.

LABORATÓRIO NACIONAL DE ENGENHARIA CIVIL. E 391: betão: determinação da resistência à carbonatação. Lisboa: LNEC, 1993.

LABORATÓRIO NACIONAL DE ENGENHARIA CIVIL. Guia para utilização de agregados reciclados grossos em betões de ligantes hidráulicos. Lisboa: LNEC, 2009.

LEITE, M. B. Avaliação das propriedades mecânicas de concretos produzidos com agregados reciclados de resíduos de construção e demolição. Porto Alegre, 2001. 270 f. Tese (Doutarado em Engenahria Civil) - Escola de Engenharia, Universidade Federal do Rio Grande do Sul, Porto Alegre, 2001.

194 Salles, P. V.; Gomes, C. L.; Poggiali, F. S. J.; Rodrigues, C. de S. 
LEVY, S. M.; HELENE, P. Durability of recycled aggregates concrete: a safe way to sustainable development. Cement and Concrete Research, v. 34, n. 11, p. 1975-1980, 2004.

LIMBACHIYA, M. C. Coarse recycled aggregates for use in new concrete. Proceedings of the Institution of Civil Engineers - Engineering Sustainability, v. 157, n. 2, p. 99-106, 2004.

LIU, Q. et al. Investigation of using hybrid recycled powder from demolished concrete solids and clay bricks as a pozzolanic supplement for cement. Construction and Building Materials, v. 73, p. 754-763, 2014.

MATIAS, D. et al. Durability of concrete with recycled coarse aggregates : influence of superplasticizers. Journal of Materials in Civil Engineering, v. 06014011, n. 5, p. 1-5, 2014.

NAGATAKI, S. et al. Assessment of recycling process induced damage sensitivity of recycled concrete aggregates. Cement and Concrete Research, v. 34, n. 6, p. 965-971, 2004.

OTSUKI, N.; MIYAZATO, S.; YODSUDJAI, W. Influence of recycled aggregate on interfacial transition zone, strength, chloride penetration and carbonation of concrete. Journal of Materials in Civil Engineering, v. 15, n. 5, p. 443-451, 2003.

PACHECO-TORGAL, F. et al. Handbook of recycled concrete and demolition waste. Cambridge: Woodhead Publishing, 2013.

PEDRO, D.; DE BRITO, J.; EVANGELISTA, L. Performance of concrete made with aggregates recycled from precasting industry waste: influence of the crushing process. Materials and Structures, p. 1-14, 2014.

POON, C.; SHUI, Z.; LAM, L. Effect of microstructure of ITZ on compressive strength of concrete prepared with recycled aggregates. Construction and Building Materials, v. 18, n. 6, p. 461-468, jul. 2004.

PROŠEK, Z. et al. Role of lime, fly ash, and slag in cement pastes containing recycled concrete fines. Construction and Building Materials, v. 201, p. 702-714, mar. 2019.

ROBAYO-SALAZAR, R. A.; RIVERA, J. F.; MEJÍA DE GUTIÉRREZ, R. Alkali-activated building materials made with recycled construction and demolition wastes. Construction and Building Materials, $v$. 149, p. 130-138, set. 2017.

RYOU, J. S.; LEE, Y. S. Characterization of Recycled Coarse Aggregate (RCA) via a surface coating method. International Journal of Concrete Structures and Materials, v. 8, n. 2, p. 165-172, 2014.

SHI, C. et al. Performance enhancement of recycled concrete aggregate: a review. Journal of Cleaner Production, v. 112, p. 466-472, 2015.

THOMAS, C. et al. Durability of recycled aggregate concrete. Construction and Building Materials, v. 40, p. 1054-1065, 2012.

THOMAS, C. et al. Macro- and micro- properties of multi-recycled aggregate concrete. Journal of Cleaner Production, v. 245, p. 118843-118863, fev. 2020.

WERLE, A. P.; KAZMIERCZAK, C. D. S.; KULAKOWSKI, M. P. Carbonatação em concretos com agregados reciclados de concreto. Ambiente Construído, v. 11, n. 2, p. 213-228, 2011.

XIAO, J. et al. Mechanical properties of concrete mixed with recycled powder produced from construction and demolition waste. Journal of Cleaner Production, v. 188, p. 720-731, jul. 2018a.

XIAO, J. et al. Utilization potential of aerated concrete block powder and clay brick powder from C\&D waste. Construction and Building Materials, v. 188, p. 117721, mar. 2018b.

ZHANG, J. et al. Influence of carbonated recycled concrete aggregate on properties of cement mortar. Construction and Building Materials, v. 98, p. 1-7, 2015.

ZHANG, S.; ZONG, L. Properties of concrete made with recycled coarse aggregate from waste brick. Environmental Science \& Technology, v. 33, n. 2, p. 482-489, 2013.

\section{Agradecimentos}

Agradecimentos à CAPES, CEFET-MG e FAPEMIG, pelo financiamento da pesquisa, às empresas ERCA, SLU-BH e HOLCIM pela doação de material de pesquisa e ao revisor Bernardo Ramos. 


\section{Pedro Valle Salles}

Departamento de Engenharia Civil | Centro Federal de Educação Tecnólogica de Minas Gerais | Av. Amazonas, 7675, prédio 18, Nova Gameleira | Belo Horizonte - MG - Brasil | CEP 3051-000 | Tel.: (31) 3319-6848 | Departamento Engenharia Aplicada | Universidade do Estado de Minas Gerais | Av. Brasília, 1304, Bau | João Monlevade - MG - Brasil | CEP 35930-314 | Tel.: (31) 3859-3200 | E-mail: pedrovallesalles025@gmail.com

\section{Camila Lacerda Gomes}

Departamento de Engenharia Civil | Centro Federal de Educação Tecnólogica de Minas Gerais | E-mail: camilalgomes@hotmail.com

Flávia Spitale Jacques Poggiali

Departamento de Engenharia Civil | Centro Federal de Educação Tecnólogica de Minas Gerais | E-mail: flaviaspitale@gmail.com

Conrado de Souza Rodrigues

Departamento de Engenharia Civil | Centro Federal de Educação Tecnólogica de Minas Gerais | E-mail: rodrigues.conrado.s@gmail.com

\section{Ambiente Construído}

Revista da Associação Nacional de Tecnologia do Ambiente Construído

Av. Osvaldo Aranha, $99-3^{\circ}$ andar, Centro

Porto Alegre - RS - Brasil

CEP 90035-190

Telefone: +55 (51) 3308-4084

www.seer.ufrgs.br/ambienteconstruido www.scielo.br/ac

E-mail: ambienteconstruido@ufrgs.br 